\title{
SINGLE PARENTING: INTERVENTIONS IN THE TRANSITIONAL STAGE
}

\author{
Kris Kissman
}

ABSTRACT: Following divorce or separation, many mother-headed families need to mourn losses, including reduced economic resources. They need to reestablish family rituals, confront such issues as time management and structural changes that can result in scapegoating or over-reliance on a parental child. Normalizing difficulties associated with parenting is important because single parents tend to internalize societal attribution of family difficulties to inadequate family structure rather than developmental stages, limited economic resources, and negative expectations about the capacity of women to head families.

Some practitioners prefer to refer to single parent families as bi-nuclear when absentee parents help raise the children (Ahrons, 1987). In reality, many one-parent families, most of whom are headed by women, do not receive financial support or assistance with childrearing. As many as $40 \%$ of single parent families do not even have a child support award and of those who do, just over half actually receive the full amount on a regular basis (US Bureau of the Census, 1989). Only one half of fathers visit their children regularly following divorce and $20 \%$ of the children of divorce see their father once a week or more (Osherman, 1986).

It is true that extended family support can be so strong that grandmothers actually co-parent their grandchildren and the single parent family is not mono-nuclear but bi-nuclear. Many children are,

Kris Kissman, $\mathrm{PhD}$, is assistant professor, School of Social Work, the University of Michigan, 1065 Frieze Building, Ann Arbor, MI 48109-1285. 
however, parented by one person and even though increasing number of parents in these families are never married and have often chosen to parent alone, many experience a difficult transitional phase following divorce or separation. Among the common treatment issues practitioners encounter in helping these families adjust to parenting alone are related to economic changes, realignment of the family structure and support utilization.

Economic changes, for example, often occur because nearly $90 \%$ of single parent families are mother-headed (US Bureau of the Census, 1986). Their average income, even when these mothers work full time, is only $50 \%$ of their male counterparts who parent alone (US Bureau of the Census, 1985). Added responsibilities of day-to-day activities, therefore, tend to be compounded by severe economic decline following divorce or separation. Family members often need to mourn the loss of a father from the home, reduced income and lowered standard of living; frequently involving loss of home, neighborhood, friends and status of the two-parent family.

During the transitional stage, the initial tendency of families to respond to changes in structure with a lowered sense of competence must be addressed. Lack of competence by members of one-parent families is often created by increased demands in terms of time, skills and energy, reduced resources, and negative societal messages about the inadequacy of the single parent household.

The practitioner can communicate positive connotations about what is possible in a restructured system. Emphasis must be placed on the family's strengths and its capacity to function as a whole and intact unit. Emotional, task, and financial support tend to be in short supply during the initial stages of single parenting because the old networks, consisting of married couples, are no longer supportive (Kissman, 1991). Bringing in fathers or male partners as rescuers is likely to affirm the families' transitional difficulties. Network intervention aimed at helping custodial parents assert their right to share co-parenting responsibilities with absentee parents can result in needed respite and financial aid for mothers and increased emotional support for the children.

Families that continue to respond to the old structure or that operate in a holding pattern, waiting to be relieved from a temporary state as single parents, are likely to experience difficulties in coping with the often long-term status of single parenting. Even though the rate of remarriage for single mothers has fallen drastically in the past 15 years and only about half of divorced women remarry, the 
universal assumption seems to be that women who are alone are in some sort of a transition (Rothblum \& Franks, 1986).

Realignment of the new system requires a gradual acceptance by family members of its new form. After the often difficult initial postdivorce period, however, many women have found renewed strength and confidence in their ability to work and to care for their families alone. Various studies have found that despite economic disaster, women after divorce significantly improved the quality of their lives (Wallerstein, 1986).

\section{AN APPROACH TO FACILITATING THE CHANGES}

In this article I discuss interventions aimed at facilitating realignment and adjustment of the single parent family following divorce or separation. Changes in the division of labor among family members, for example, may require that the executive system give up some conventional expectations, tasks, and functions in order to provide increased support, nurturance, and socialization of autonomous and responsible family members. Re-establishing family rituals, including regularly scheduled family sessions, time management, normalization of the adolescent period and family/practitioner contract negotiations are additional strategies used to facilitate collaboration and cohesiveness among members of the single parent family.

Not all single parent families experience transitions in a sequential or orderly fashion. Many experience multiple transitions simultaneously when new partners become part of the family shortly after the initial parental separation. The effect of divorce on the children is greatly contingent on the relationship between mother and father and these relationships become more complex when sequential stages of transition do not take place but separation then reconstitution, of the family occurs within a very short period of time. The parameters of single parenting do not include other diverse family forms, such as remarried families, however, and cohabiting parents and their families are two-parent systems.

\section{FUNCTIONAL REALIGNMENT OF THE INTERNAL STRUCTURE}

Realignment issues are associated with family members' ability to respond to the new realities of the one-parent system. In the early 
life-cycle of the family when the children are young the practitioners helps the family develop and utilize extended family and extra-familial support systems to the fullest extent possible.

Regardless of the children's age, they tend to move closer to the executive systems following divorce or separation. During this often emotionally charged transitional stage, one child, usually the oldest or opposite gender, tends to take on the identity of the absentee parent. The child who resembles the absentee parent in manner and appearance often becomes the recipient of parental anger that is projected on the child.

Such scapegoating can cause a great deal of pain and conflict in the parent/child interaction. It can lead to unrealistic expectations of the child's ability to comply, harsh discipline, and punitive parental behavior toward the child. Empathy training to help the parent understand the needs of the child is coupled with helping the mother move out of the victim role and toward greater acceptance and appreciation of the single parent role. Unfortunately, such resentment toward a child and the absentee parent prevents much collaboration between parents, so that parents who are very much in need of support are left to parent alone.

Intergenerational work tends to center around separation issues also. Parents who have difficulty empathizing with the needs of their child for an autonomous existence are likely to have a difficult time making their needs known to their own family of origin. Cross-generational patterns of conflicts associated with adolescent needs for individuation become particularly challenging in the one-parent family where over-utilization of the parental child in the capacity of co-parent becomes problematic.

The term parental child is usually pejoratively defined in the family therapy literature as over-reliance on a child to make decisions and to perform parental tasks, such as care of younger siblings, to the extent that peer relations and other developmental needs are sacrificed. Not only in the single parent household, but also in dual income families as well, parents are encouraging their children to be self-responsible and to share in family tasks at an early age. The boundaries between the sibling and executive system become more diffused as children increasingly participate in decision-making, tasks, and responsibilities. The concern is voiced by many practitioners that childhood is cut short and children are rushed into adulthood too soon.

Increased responsibility on the part of children in today's families 
can be a strength and a potential hazard. In cases where responsibilities interfere with the development of individual autonomy, including peer activities, the practitioner must strongly advocate for the child's needs.

\section{CHANGES IN THE DIVISION OF LABOR}

Changes in the division of labor among family members involve reassignment of family tasks to minimize the burden on the parent who often is the sole provider of family resources. Children as young as four and five years of age can perform simple household tasks such as picking up and dusting. The practitioner helps the mother to use contract negotiation as a means to allocate increased responsibilities as the children grow older.

A written consensual agreement between the mother and child sets out tasks to be performed and reward systems based on tokens and other reinforcement that are both affordable for the family and desired by the children. These contracts need to reflect realistic expectations of family members' ability to carry out tasks and they must be flexible enough to leave room for renegotiations. A 13 yearold, for example, may contract to do the laundry and some housecleaning, but should not be expected to perform most of the household chores.

\section{TIME MANAGEMENT}

Time management involves careful weighing of the costs and benefits of many of the functions performed by mothers in more "traditional" families. If such tasks prove too costly in terms of energy expenditures, the practitioner needs to give family members permission to cease performing some household tasks. Mothers who tend toward perfectionism need to be reminded that many chores can be eliminated without dire consequences to the family's well-being. Pastry-baking and coupon-clipping can stretch the family dollar and this is often imperative in the one-parent home, but the mother herself must make careful decisions about the worth of each chore in terms of benefit to the family and expenditure of time.

Reduction of such tasks as ironing and changing the bed linens less than once per week can be reframed as energy-saving devices 
rather than sloppy housekeeping. Time management requires that the advice of well-meaning family and friends about the role of the "good" mother be dismissed and the mother be empowered to firm boundaries around her decision-making capacities. Studies have found that mothers who have difficulties giving up some of the tasks they performed before becoming employed full time risk role overload, stress and burnout (Krausz, 1986). Many single parents, of course, are already in the labor force at the time of divorce or separation and did not enjoy co-parental collaboration in the discharge of childrearing and domestic tasks during their marriage. Nevertheless, the responsibilities of sole wage earner/caregiver frequently seem overwhelming to such single parents in the transitional stage following divorce or separation.

Redefining the mother's role is especially important during later life-cycle stages of the family when she moves into an advisory role and family members increasingly participate in decision-making regarding daily activities and chores. The sole caregiver/wage earner who is torn between career goals and the needs of her family must be reminded that the best parent is the one who encourages self-reliance and sufficiency while making herself available for needed emotional informational support. Attentive listening, encouraging, communicating hope, and acceptance are interpersonal practice skills applicable to the nurturing parental role as well.

\section{REDEFINING FAMILY RITUALS}

Declining economic resources tend to create changes in family rituals such as vacations, dining out, celebration of important events, and so forth. The transitional phase following separation or divorce involves reestablishing ways of celebrating important events even in cases where economic resources have not declined significantly. The practitioner helps the family explore alternate ways of marking important milestones through rituals such as local mini-vacations and picnics. Often, family members need to be reminded to focus on the positive elements of change such as more freedom associated with unilateral decision-making and less conflictual relationships in the home.

Regularly scheduled family sessions can become part of important rituals that help reestablish cohesiveness of the new structure. The practitioner serves as a teacher and a mediator in helping to 
establish the participative decision-making often found to be prevalent in the mother-headed family (Hartman, 1986). This non-hierarchical process does not eliminate the power of the executive system but divides that power among family members in a more egalitarian way than is the case in more authoritarian family systems. Democratic problem-solving and negotiation skills are strengthened when children are encouraged to bring everyday problems and suggestions up for discussion.

The practitioner can suggest that family members engage in behavioral rehearsal during treatment sessions as means to enhance listening skills and mutual respect for individual differences of opinion. These skills are an important part of all family interactions, including family sessions. Parents need to have, for example, realistic expectations of their children's need for autonomy. Parental expectations for complete obedience sometimes must be modified from "getting my adolescent to keep his room clean" to "being able to live together for the next two years". Intervention objectives are then reformulated to reflect steps toward resolution of conflicts.

\section{NORMALIZING THE ADOLESCENT PERIOD}

Single parents need to be reminded that although adolescence is not an illness, it is usually a difficult period for all family members. Normalizing this phase of the family life-cycle helps to counter the worried-well syndrome many single parents exhibit as a result of internalized negative view of the capacity of mothers to parent alone. Mothers' worries extend to all phases of the family life-cycle and are not limited to adolescent individuation, as many problems and ambivalences associated with parenting in general surface during this challenging detachment phase.

During the adolescence period, parent/child value systems cannot be expected to be in harmony. Some values, such as use of drugs, cannot be compromised, however, and these differences can lead to an impasse in the conflict resolution process within the family. Interventions are still focused on the goal of preservation of the family unit until the teenager has completed schooling.

Referrals to self-help groups such as Parenting Together or Tough Love have been helpful to some parents who are experiencing difficulties in defining attainable expectations and holding their teens accountable for their own actions. Support groups offer parents 
the opportunity to ventilate feelings of frustrations frequently associated with parenting teenagers and letting go of some of the dreams we have for them. It is not unusual for parents to displace their own hopes and aspirations onto their growing children. When compared to the high objectives of aspiring academic achievement and career goals, the harsh reality of a teen out of control is difficult to confront.

\section{FAMILY/PRACTITIONER CONTRACT AGREEMENTS}

A participatory relationship between parent and child allows for the formulation of working agreements that would be difficult to establish in more authoritative family structures. The practitioner can help formulate oral or written working agreements between mother and child. In this case, the agreement is to accomplish objectives leading to the goal of living together until the adolescent completes high school. The working agreement comprises jointly formulated goals meeting the criteria of being realistic, attainable, measurable and time limited (Garvin \& Seabury, 1984). The goal reflects a desired outcome at the end of the intervention period and it is clearly defined.

An intermediate goal of reducing shouting from 3-4 times weekly can be helpful in breaking down the sequence of the desired outcome so that success can reinforce step by step progress toward the goal. At the end of three months the number of shouting instances can be realistically expected to drop down to once per week with the help of intervention. This intermediate goal can then lead to an ultimate goal of living together for the next two years. These are outcome goals, reflecting desirable and mutually agreed on changes in the clients life during and at the end of the treatment sessions (i.e., moving toward the ability to live together).

The goal attainment scale can be used to assess the extent to which outcome goals are accomplished:

$*=$ at intake

$\mathrm{V}=$ end of treatment and follow-up

Above Expected Level

$\mathrm{V}$ (6 month follow

up) Teenager

is residing at

home with no

support services

and manageable

conflict level 
VTeenager is residing at home with help of parent/child support group

Below Expected Level *Teenager is at risk of being placed outside the home due to family conflicts

Process goals, sometimes called objectives, reflect the tasks the client and worker must accomplish in order to meet the desired outcome goal(s). Task attainment is easy to assess because tasks have either been accomplished, partially accomplished, or not accomplished within a specific time period. An example of a process agreement leading to the desired outcome of living together for the next two years might include the following tasks:

The mother and teenager agree to attend family sessions to learn conflict resolution and coping skills. The working agreement between the parent/child dyad interconnects with the practitioner contract. The mother and teenager agree to participate in an initial 6-week session designed to accomplish the following objectives:

The Mother agrees to respect the teen's "space" by not making comments about his room.

The Son agrees to engage in one weekly cleaning session of the room, with specified tasks to be completed and monitored by the therapist.

The Mother and son agree to learn to recognize signs of anger and to issue a "time-out" signal when angry.

The Mother and son agree to practice listening without interrupting during treatment sessions.

The Mother and son agree to engage in forgiveness ritual during treatment sessions. This involves burying past grudges, mutual forgiveness and a commitment toward empathetic understanding of one different point of view during a one-week period.

The practitioner's objectives are to teach the enabling conflict resolution skills and to serve as a mediator of the parent/child conflicts. Homework assignments can help family members practice these skills and also provide continuity between the treatment sessions and day-to-day interactions. The contract agreement is likely to need renegotiation at the end of the 6 -week period. The formulation of new objectives may include a referral to a parent/teen support 
group and other community resources as well as strengthening family and peer group support systems.

\section{SUMMARY}

Some of the issues in the transitional stage following divorce or separation are similar to those experienced by families in general. Extended family and extra-familial supports are often critical in the early life cycle of the single parent family when the children are young and the family must quickly adjust to the new structure. Throughout the life cycle of the family, mourning losses resulting from reduced economic resources, reestablishing family rituals, time management and structural changes that result in scapegoating or over-reliance on the parental child are among the issues many single parents confront during the transition following divorce and separation.

Normalizing the difficult period associated with adolescence is particularly important because single parents tend to internalize societal attribution of family difficulties to inadequate family structure rather than developmental stages, limited economic resources, and negative expectations about the capacity of women to head families. Contract negotiations between parent and children are based on the ability of all parties to increase levels of empathetic understanding and tolerance for cross-generational value and need differences. These contracts intersect with verbal agreements between the family and the practitioner for joint attainment of objectives leading to desired outcome.

\section{REFERENCES}

Ahrons, C. R., \& Rodgers, R. H. (1987). Divorced families: Meeting the challenge of divorce and remarriage. New York: Norton.

Garvin, C. D., \& Seabury, B. (1984). Interpersonal practice in social work: Processes and procedures. Englewood Cliffs, NJ: Prentice Hall.

Hartman, A. (April, 1986). Families in theory and practice. Keynote Address to the Second Annual Doctoral Symposium. Ohio State University College of Social Work.

Kissman, K. (1991). Feminist-based social work with single parent families. Families in Society, 72(1), 23-27.

Krausz, S. L. (1986). Sex roles within marriage. Social Work, 31, 457-464. 
KRIS KISSMAN

Osherson, S. (1986). Finding our fathers: The unfinished business of manhood. New York: The Free Press.

Rothblum, E., \& Franks, V. (1986). Custom fitted straight jackets: Perspectives on women's mental health. In J. Figueira-McDonough \& R. Sarri (Eds.), The trapped woman (pp. 348-374). Newbury Park, CA: Sage Publications.

US Bureau of the Census (1985). Money, income, and poverty status of families in the US: 1984. Washington, DC: Government Printing Office.

US Bureau of the Census (1986). Household and family characteristics. Current Population Reports (Series P-20, No. 419). Washington, DC: Government Printing Office.

US Bureau of the Census (1989). Marital status and living arrangements: March 1988. Current Population Reports (Series P-20, No. 433). Washington, DC: Government Printing Office.

Wallerstein, J. C. (1986). Women after divorce: Preliminary report from a ten-year follow-up. American Journal of Orthopsychiatry, 56, 65-77. 